the passage of the smaller molecules is delayed because they enter the micropores of the material. (2) The deposits hinder exchange by acting like a porous sponge preventing close contact of the plasma with the membrane. This would limit the passage of only the small molecules since normally they are rapidly transported through the membrane and thus reduce the concentration gradient. This explanation would be consistent with the observation that the dialysance of small molecules is much more dependent on the rate of flow than is the dialysance of large molecules.

We wish to thank Dr. R. Kattermann, chief of the central laboratories, for the use of the autoanalyser, and especially $W$. S. Hüsken and his dialysis nursing staff for their expert help.

\section{References}

Bell, R. P., and Figueroa, J. E. (1970). British Medical fournal, 1, 788. Evans, D. B., and Lines, J. G. (1970). British Medical fournal, 1, 786.
Folin, T., and Wu, C. J. (1949). In Practical Physiological Chemistry, ed. P. B. Hawk, B. L. Oser, and W. H. Summerson, 12th edn., p. 506. New York, Blakiston.

Hartitzsch, B., Hoenich, N. A., and Kerr, D. N. S. (1971). Proceedings of the European Dialysis and Transplant Association, 8, 401.

Kramer, P., Quellhorst, E., Henning, H. V., and Scheler, F. (1970). In Aktuelle Probleme der Dialyserverfahren und der Niereninsuffizienz, III Symposion Innsbruck, 1969, ed. P. V. Dittrich and K. F. Kopp, p. 15. Friedberg Hessen, Bindernagel.

Kramer, P., Tönnis, H. J., Eichelberg, B., Kattermann, R., and Scheler, F. (1971). Proceedings of the European Dialysis and Transplant Association, 8,460 .

Kramer, P., Eichelberg, B., and Scheler, F. (1972). Medizinische Technik.

In press.
Lavender, A. R., Markley, F. W., and Forland, M. (1968). Proceedings of the European Dialysis and Transplant Association, 5,21 .

Marsh, W. H., Fingerhut, B., and Miller, H. (1965). Clinica, Chemistry,

11, 624. J. D. S. (1971). Proceedings of the European Dialysis and Transplant Association, 8, 445.

Pollard, T. L., Barnett, B. M. S., Eschbach, J. W., and Scribner, B. H. (1967). Transactions. American Society for Artificial Internal Organs, $13,24$.

Shaldon, S., Silva, H., and Rosen, S. M. (1964). British Medical fournal, 2,411 .

Tchetchik, M., Nakamoto, S., and Kolff, W. J. (1966). Fournal of the American Medical Association, 196, 451

$\$$

\title{
Amphetamine and Other Non-opioid Drug Users Attending a Special Drug Dependence Clinic
}

\author{
R. GARDNER, P. H. CONNELL
}

British Medical fournal, 1972, 2, 322-325

\section{Summary}

This paper reports the findings in 104 users of nonopioid drugs (mainly amphetamines) attending a drug dependence clinic in London between March 1968 and February 1969 in relation to demographic characteristics, forensic, psychiatric, and medical histories, clinical groups, management policy, and the use of biochemical tests for the presence of drugs in the urine.

Nearly one-third gave a history of starting amphetamine misuse while at school $(13.5 \%)$ or within a year of leaving school (16.3\%). Amphetamine psychosis had occurred in $35 \%$ of cases and was a more frequent complication of intravenous than of oral abuse. Except for a small proportion of older patients who have become dependent on drugs originally prescribed for therapeutic purposes, "maintenance therapy" is most unlikely to be effective in the treatment of amphetamine dependence. Nevertheless, about one-quarter of the younger patients in this series had obtained prescriptions from general practitioners after starting their drug abuse illicitly. There is a strong case for the compulsory notification under the Misuse of Drugs Act (1971) of persons dependent on amphetamines.

\section{Introduction}

The Dangerous Drugs Act (1967) provided for the compulsory notification of patients dependent on specified drugs of addiction and the setting up of special clinics for their treatment. The Regulations giving effect to the Act were in the first place limited to drugs (mainly opioids) covered by Section 11 of the Dan-

Drug Dependence Clinical Research and Treatment Unit, Bethlem Royal and Maudsley Hospitals, London

R. GARDNER, M.B., B.S., M.R.C.P., Senior Registrar

P. H. CONNELL, M.D., M.R.C.P., Physician gerous Drugs Act (1965), which seemed to present the most urgent and serious problem. Misuse of and dependence on other drugs have continued to be dealt with mainly by the general medical and psychiatric services.

From the outset the Bethlem Royal and Maudsley Hospitals jointly provided both outpatient and inpatient services for all forms of drug dependence (excluding alcohol, which was already dealt with in other facilities of the hospitals) in order that teaching and research could cover the total field (Connell, 1968d, 1970). An evening clinic for drug users, originally started in 1964 by one of us (P.H.C.), was reserved for non-opioid users-apart from intravenous users of amphetamines, who were seen at other times (Connell, 1968c).

The findings in opioid users attending the joint hospitals have been described elsewhere (Gardner and Connell, 1971), as has their initial management (Gardner and Connell, 1970). This paper is concerned with the demographic and clinical characteristics, patterns of drug misuse, and initial management of patients abusing non-opioid drugs (mainly amphetamines) who were seen during the first year of operation of the 1967 Act.

\section{Patients and Methods}

One hundred and four consecutive patients presenting with non-opioid drug abuse at this unit between 25 March 1968 and 28 February 1969 were studied. Data were obtained from various sources, and examination of the patient included the use of a standard questionnaire concerning drug usage (Connell and Gardner, unpublished) and full evaluation of the medical, drug, and psychiatric histories and physical and mental state. In 90 cases a specimen of urine was obtained on first attendance and was tested for amphetamines by a gas chromatographic method and for the barbiturate and opioid groups of drugs by thinlayer chromatography.

Data obtained from the patients' own statements, physical examination, urine examination, supporting data from G.P.s, probation officers, spouses, etc., and from finding the patient in possession of drug showed that 35 were intravenous methamphetamine users, 65 were amphetamine tablet users, three 
were dependent on barbiturates, and one was a chloroform sniffer. Six patients (two methamphetamine and four amphetamine tablet users) had stopped taking these drugs before they were examined. A number of patients admitted to the use of other drugs, including opioids, and the urine of four amphetamine users was found to be positive for opioid drugs. They have not been excluded from this series because their main drug of dependence was an amphetamine for which they requested a prescription at the clinic. After the withdrawal of ampoules of methamphetamine from retail sale in October 1968 the number of new intravenous users of this drug attending the clinic declined, and none were seen after December 1968.

\section{Demographic Characteristics}

Only one of the 104 patients was born outside the United Kingdom or the Republic of Ireland. Their mean age was 23.1 (S.E. \pm 0.79 ), with a range of $15-51$ years. The ratio of males to females was $4: 1$. There was no sex difference in patterns of drug misuse. However, the female tablet users (mean age 33.1 ), who included eight housewives, were significantly older than the male tablet users (mean age 18.1, $t=2 \cdot 141, P<0.05$ ). Only 36 patients $(34.6 \%)$ were working full-time and $5(4.8 \%)$ part-time at first attendance. Employment status bore no relation to age, sex, or duration or pattern of drug misuse. Other demographic data are summarized in Table $I$.

TABLE I-Demographic Characteristics at First Attendance of 104 Non-opioid Users

\begin{tabular}{|c|c|c|c|}
\hline & & $\begin{array}{l}\text { No. of } \\
\text { Patients }\end{array}$ & $\%$ \\
\hline $\begin{array}{l}\text { Area from } \\
\text { which } \\
\text { referred }\end{array}$ & $\begin{array}{l}\text { S.E. London } \\
\text { S.W. London } \\
\text { Rest of London } \\
\text { Outside London }\end{array}$ & $\begin{array}{l}36 \\
19 \\
30 \\
19\end{array}$ & $\begin{array}{l}34 \cdot 6 \\
18 \cdot 3 \\
28 \cdot 8 \\
18 \cdot 3\end{array}$ \\
\hline $\begin{array}{r}\text { Referring } \\
\text { agency }\end{array}$ & $\begin{array}{l}\text { Other treatment clinic or hospital } \\
\text { Social agencies } \\
\text { G.P. (non-prescribing) } \\
\text { Prescribing G.P. } \\
\text { Self }\end{array}$ & $\begin{array}{l}35 \\
24 \\
20 \\
15 \\
10\end{array}$ & $\begin{array}{l}33 \cdot 7 \\
22 \cdot 1 \\
19 \cdot 2 \\
14 \cdot 4 \\
10 \cdot 6\end{array}$ \\
\hline $\begin{array}{l}\text { Age } \\
\text { groups }\end{array}$ & $\begin{array}{l}14-19 \\
20-24 \\
25-29 \\
30+\end{array}$ & $\begin{array}{l}47 \\
29 \\
11 \\
17\end{array}$ & $\begin{array}{l}45 \cdot 2 \\
27.9 \\
10 \cdot 6 \\
16 \cdot 3\end{array}$ \\
\hline Sex & $\begin{array}{l}\text { Male } \\
\text { Female }\end{array}$ & $\begin{array}{l}85 \\
19\end{array}$ & $\begin{array}{l}81 \cdot 7 \\
18 \cdot 3\end{array}$ \\
\hline $\begin{array}{l}\text { Social } \\
\text { class of } \\
\text { patient }\end{array}$ & $\begin{array}{l}\text { I+II } \\
\text { III } \\
\text { IV }+ \text { V } \\
\text { Unclassified }\end{array}$ & $\begin{array}{l}15 \\
21 \\
47 \\
21\end{array}$ & $\begin{array}{l}18.1 \\
25.3 \\
56.6 \\
-\end{array}$ \\
\hline
\end{tabular}

- Registrar General's Classification 1957.

\section{Forensic History}

Seventy-five patients $(72 \cdot 1 \%)$ had been found guilty of offences, $60 \%$ of which were unconnected with the Dangerous Drugs Acts. Twenty had juvenile convictions only and 25 both juvenile and adult convictions. Among those with no forensic record the proportion of females was significantly higher than in the whole series of patients $(P<0.0005)$. Twenty-seven patients $(26 \%)$ were subject to probation orders at the time of first attendance.

\section{Medical History}

Four patients had a history of abscess and five of jaundice as complications of drug misuse, and $35(33.7 \%)$ had taken overdoses, 16 with suicidal intent. Accidental overdose (19 cases) had occurred most freqently in tablet users $(18$, of whom seven had required hospital admission). Only nine patients had been admitted to hospital for the purpose of withdrawal of drugs apart from those suffering from accidental overdose.

\section{Psychiatric History}

A background of behaviour disorder and adolescent problems before as well as after starting to misuse drugs was not uncommon. Five patients gave a history of depressive illness which had been treated with electric convulsion therapy and two were found to be suffering from a paranoid psychosis unconnected with drug taking. Twenty-one $(20 \cdot 2 \%)$ had made a suicidal attempt or gesture. Thirty-six (34.6\%) had experienced paranoid symptoms from the use of amphetamines. Proportionately more of the group injecting methamphetamine (20 out of 35) had had these symptoms than of those taking amphetamines orally (16 out of 65). This difference is statistically significant $\left(\chi^{2}=\right.$ 8.69; $P<0.005$ ). Amphetamine psychosis was, however, a rare cause of hospital admission (only two cases). Irritability and depression had been experienced by 36 patients $(34.6 \%)$ in this series as a result of the withdrawal effects of central nervous system stimulants. It is not clear how many of the reported suicidal attempts occurred in this withdrawal phase. The symptoms commonly produced by amphetamines-aggression, sleep disturbance, appetite, and weight loss-were more frequent and more severe in the injection group than among oral users.

\section{Drug History}

The mean age of onset of drug misuse was 18.6 years (S.E. \pm $0.62)$, with a range of $13-42$ years. Fourteen patients $(13.5 \%)$ had started drug-taking at school and $17(16.3 \%)$ during the school-leaving year (age 15). The early onset in most followed the socio-cultural pattern of illicit weekend amphetamine misuse (Connell, 1964) whereas those with a later onset had often first received their drug of dependence from a medical practitioner. Cannabis, which was commonly used by the younger patients, had not been used by the older tablet users. The duration of progress from onset of drug misuse to daily misuse generally exceeded one year (39 cases, or $63 \%$ of those for which such information was available.) Of the 18 patients who claimed sporadic use only, six had been abusing drugs for less than a year at the time of first attendance. The older tablet users had mostly received a daily prescription from the start. The mean duration of drug use for the series was 3.1 years (range 6 months to 16 years), and was longer for the older tablet users than for the younger patients $(r=0.644 ; P<0.001)$ (see Table II).

\section{Drug Misuse at First Attendance}

The presenting patterns, source of drug, and results of urine testing are shown in Tables II, III, and IV. Most of the patients who were currently misusing opioids were progressing from amphetamine to opioid misuse. Only two claimed daily use of opioids (Table III). The results of urine testing for drugs (Table IV) supported the statements of those who claimed to have stopped using drugs or to be sporadic users only. However, 20 of the 68 tested who claimed daily use of a drug gave negative results; three of these were misusing drugs (ephedrine, phenmetrazine, and chloroform) for which a test was not done and some of the remainder were probably sporadic users falsely claiming daily use in order to obtain a prescription. Three of the latter had a positive urine test at a later date.

\section{Management}

With the exception of one older tablet user who was referred back to her general practitioner and one patient who was off drugs and was not given a further appointment, all (including those awaiting admission and those who refused admission) were advised to continue attendance at the clinic. Six patients were admitted after their first or second attendance. Thus 96 
patients had the opportunity to attend more than twice, and $\mathbf{4 0}$ did so; six of these were awaiting admission and three were off drugs. Of the remaining 31,18 had received a prescription from the clinic on a previous occasion, an association that is statistically significant $\left(\chi^{2}=12.69 ; P<0.005\right)$, while the 13 who attended more than twice without receiving a prescription were either on probation or due to appear in court. This finding suggests that subsequent attendance often depended on receiving a prescription or on court requirements. Antidepressants were prescribed to six patients attending the clinic

TABLE II-Drug History and Initial Management in 104 Patients

\begin{tabular}{|c|c|c|c|}
\hline & & No. & $\%$ \\
\hline $\begin{array}{l}\text { First drug } \\
\text { misused }\end{array}$ & $\begin{array}{l}\text { Amphetamines } \\
\text { Amphet./barb. pill } \\
\text { Amphet. tab. } \\
\text { Methamphetamine } \\
\text { Amphet. inhaler } \\
\text { Other drugs* }\end{array}$ & $\begin{array}{r}91 \\
58 \\
26 \\
5 \\
2 \\
13\end{array}$ & 87.5 \\
\hline $\begin{array}{l}\text { Age first } \\
\text { misused }\end{array}$ & $\begin{array}{l}13-19 \\
20-24 \\
25+ \\
\text { Not known }\end{array}$ & $\begin{array}{r}73 \\
11 \\
14 \\
6\end{array}$ & $\begin{array}{r}74 \cdot 5 \\
11 \cdot 2 \\
14 \cdot 2 \\
-\end{array}$ \\
\hline $\begin{array}{l}\text { Duration of } \\
\text { drug } \\
\text { misuse } \\
\text { (years) }\end{array}$ & $\begin{array}{l}<1 \\
1-2 \\
2-5 \\
5+ \\
\text { Not known }\end{array}$ & $\begin{array}{r}17 \\
11 \\
40 \\
32 \\
4\end{array}$ & $\begin{array}{l}17 \cdot 0 \\
11 \cdot 0 \\
40 \cdot 0 \\
32 \cdot 0 \\
-\end{array}$ \\
\hline $\begin{array}{l}\text { Duration of } \\
\text { daily } \\
\text { misuse } \\
\text { (years) }\end{array}$ & $\begin{array}{l}<1 \\
1-3 \\
3+ \\
\text { Not applicablet } \\
\text { Not known }\end{array}$ & $\begin{array}{l}35 \\
21 \\
14 \\
24 \\
10\end{array}$ & $\begin{array}{l}37 \cdot 2 \\
22 \cdot 3 \\
14 \cdot 9 \\
25 \cdot 5 \\
-\end{array}$ \\
\hline $\begin{array}{l}\text { Past history } \\
\text { of } \\
\text { intravenous } \\
\text { use }\end{array}$ & $\begin{array}{l}\text { Heroin } \\
\text { Methadone } \\
\text { Morphine } \\
\text { Methamphetamine } \\
\text { Dexamphetamine } \\
\text { Barbiturates: Mandrax } \\
\text { Not applicable }\end{array}$ & $\left.\begin{array}{r}36 \\
8 \\
4 \\
40 \\
3 \\
6 \\
64\end{array}\right\}$ & 38.5 \\
\hline $\begin{array}{l}\text { Source of drug } \\
\text { at first } \\
\text { attendance }\end{array}$ & $\begin{array}{l}\text { Illegal } \\
\text { General practitioner } \\
\text { Not known }\end{array}$ & $\begin{array}{l}54 \\
38 \\
12\end{array}$ & $\begin{array}{l}51 \cdot 9 \\
36 \cdot 5 \\
11 \cdot 6\end{array}$ \\
\hline $\begin{array}{l}\text { Initial } \\
\text { management }\end{array}$ & $\begin{array}{l}\text { Attendances }\left\{\begin{array}{l}1 \\
2 \\
3-18\end{array}\right. \\
\begin{array}{c}\text { No. prescribed } \\
\text { unissions (drug-dependence }\end{array}\end{array}$ & $\begin{array}{l}44 \\
20 \\
40 \\
23 \\
18\end{array}$ & $\begin{array}{l}42 \cdot 3 \\
19 \cdot 2 \\
38 \cdot 5 \\
22 \cdot 1 \\
17 \cdot 3\end{array}$ \\
\hline
\end{tabular}

* Cannabis 9; barbiturates 2; opium 1; and chloroform 1 .

+6 off drugs +18 sporadic users at first attendance.

TABLE III-Pattern of Drug Misuse in 103 Non-opioid Users*

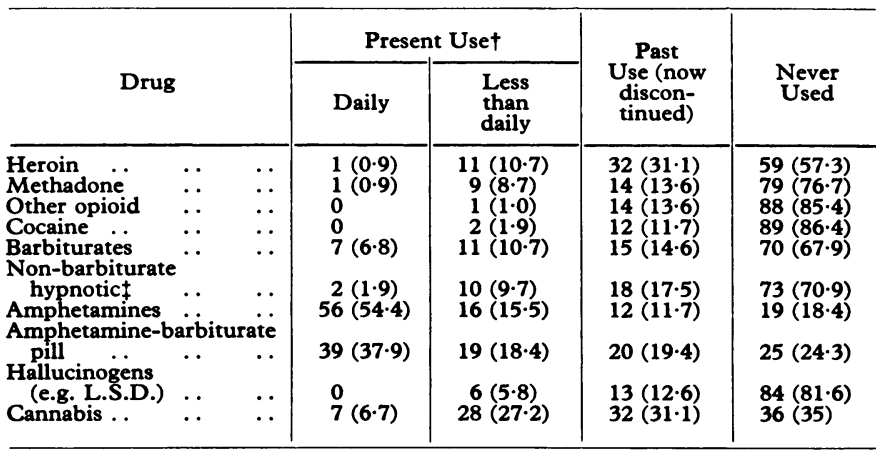

Percentages are given in parentheses.

Questionnaire not administered to one patient.

Within one month before first attendance.

$\ddagger$ Mandrax (methaqualone and diphenhydramine) had been misused by $58 \%$ of this group.

TABLE IV-History and Urine Tests at First Attendance in 104 Non-opioid Users

\begin{tabular}{|c|c|c|c|c|c|c|}
\hline \multirow{2}{*}{\multicolumn{3}{|c|}{ History }} & \multicolumn{3}{|c|}{ No. of Patients } & \multirow{2}{*}{ Total } \\
\hline & & & \multirow{2}{*}{$\begin{array}{c}\text { Negative } \\
\begin{array}{c}6 \\
11 \\
20\end{array}\end{array}$} & \multirow{2}{*}{$\begin{array}{c}\text { Positive } \\
- \\
48\end{array}$} & \multirow{2}{*}{$\frac{\text { No. Test }}{\overline{2}}$} & \\
\hline $\begin{array}{l}\text { Off drugs } \\
\text { Sporadic } \\
\text { Daily .. }\end{array}$ & $\because$ & $\begin{array}{l}. \\
\because\end{array}$ & & & & $\begin{array}{r}6 \\
18 \\
80\end{array}$ \\
\hline Total & .. & .. & 37 & $53^{*}$ & 14 & 104 \\
\hline
\end{tabular}

-Methamphetamine 18, amphetamine 11, amphetamine and barbiturate 17, morphine 2, methadone 2, and barbiturate 3 . and the drug of dependence to only four on a regular basisthat is, on more than two occasions (see Table II).

\section{Clinical Grouping}

Apart from the single chloroform sniffer, the patients fell into three clinical groups: the older tablet users, the younger tablet users, and the intravenous users.

\section{OLDER TABLET USERS}

There were eight women and six men in this group. All were aged 30 or more (out of a total of 17 patients in this age group), the women being middle-aged housewives. One was off drugs, while 11 were dependent on amphetamines and two on barbiturates, claiming daily usage. Ten, including the eight housewives, had first received a prescription from a medical practitioner for depression (7), slimming (1), or insomnia (2). Dosage of amphetamines ranged from 1 to 12 tablets ( 5 to $60 \mathrm{mg}$ ) daily. Tolerance had developed in all the amphetamine users except for two housewives who had restricted the dose to one and three tablets daily respectively for years. Only one of the amphetamine users admitted to paranoid symptoms.

Management of the older age group (Connell, 1966) included inpatient admission (three cases) or the regular prescription of amphetamines (two cases by the clinic and three by the general practitioner, two of the latter patients continuing to attend the clinic). The two patients dependent on barbiturates were often intoxicated, one misusing more than $800 \mathrm{mg}$ daily.

\section{YOUNG TABLET USERS}

Of the 54 patients in this group, only two had first received amphetamines from a medical practitioner, one for anxiety and one for slimming. Two others had been prescribed ephedrine for asthma and went on to amphetamines. Three had stopped taking drugs when first seen. The 16 sporadic users had always misused illicit drugs at weekends and none were self-referrals. Usually they were referred by courts or probation officers or attended because of the concern of their parents on account of staying out all night, keeping company with a "bad lot," irritability, or aggression or after some complication of drug misuse. Their management was conducted along the lines suggested by Connell (1968a) and seven attended more than twice. None received their drug of misuse, nor were any offered admission to hospital.

The 35 daily users had started illicitly at weekends (except in four cases) and gradually extended their drug misuse throughout the week, mainly to counter the withdrawal depression and irritability induced by the amphetamines. Once drug-dependent they had obtained their supplies from general practitioners, four privately. Some claimed abuse of up to 50 tablets a day and had marked sleep disturbance, weight loss, and paranoid symptoms. As outpatient withdrawal of drugs was impracticable (Connell, 1966), all were offered inpatient treatment and nine accepted; one received reducing amounts of amphetamines until then.

\section{INTRAVENOUS USERS}

Of the 35 patients in this group, two were off drugs and two were sporadic and 31 daily users. Most had either misused heroin in the past or were changing to opioid misuse (Table III). Injection of crushed amphetamine tablets or amphetamine sulphate powder was rarely reported (five cases). Fifteen $(42.9 \%)$ were obtaining methamphetamine illicitly and six by private prescription, the source not being stated in the remaining cases. The claimed dosages used were 1-15 ampoules daily $(30-450 \mathrm{mg})$. The intravenous users were often irritable and 
aggressive (verbally), particularly when refused drugs, and most did not reattend. None was prescribed the drug of dependence and all but the two who had stopped taking methamphetamine at the time they were first seen were offered admission to the inpatient unit; five accepted.

\section{Discussion}

The clinical groupings of amphetamine users in this series correspond with previous descriptions of United Kingdom tablet users (Connell, 1964, 1965a, 1968d; Sharpley, 1964; Kiloh and Brandon, 1962; Scott and Willcox, 1965) and intravenous users (Hawks et al., 1969).

A comparison of the 100 amphetamine with 107 opioid users attending this clinic (Gardner and Connell, 1971) showed that the former group was younger and contained fewer with a social class I-II background, and more of its older tablet users had a "therapeutic onset" of drug use. Infective complications were fewer in the intravenous methamphetamine users than in the opioid group, probably because of a shorter duration of drug use. Proportionately fewer of those on amphetamines had been admitted to hospital for drug withdrawal. The number of court offences in both groups was similar but the amphetamine group contained proportionately more unrelated to the Drugs Acts. Here again a shorter duration of drug misuse may have been an important factor.

\section{AMPHETAMINES AND DELINQUENCY}

The relation between amphetamine misuse and delinquency is complex and the number of offences under the Drugs Acts is unlikely to be a reliable indicator. Social consequences as a result of amphetamine taking (Connell, 1966) were noted in this series, although there was no serious or dangerous crime as described in Sweden (Rylander, 1966). The available data supported the view (Scott and Willcox, 1965) that delinquency and drug misuse often have common sources of origin. Nevertheless, the impression was gained with both outpatients and inpatients that those taking large doses of amphetamines tended to be more restless, agitated, and verbally aggressive than other drug users.

\section{AMPHETAMINE PSYCHOSIS}

It is likely that the appearance of psychotic symptoms is related to dose (Connell, 1958), speed of absorption, and other factors, including frequency of administration, rather than to daily as opposed to sporadic use. The incidence of such psychotoxic effects was rather less than in the series reported in Sweden by Inghe (1969) and in the U.S.A. by Kramer et al. (1967), in which larger doses of intravenous amphetamines were used, and in a United Kingdom series of methamphetamine users (Hawks et al., 1969) probably for similar reasons. The error of misdiagnosing paranoid schizophrenia in patients covertly misusing amphetamines (Connell, 1958) was unlikely in a clinic where all patients were known drug users, but in such a setting psychotic symptoms should not all be attributed to drug effects. Thus two amphetamine users were diagnosed as suffering from paranoid schizophrenia after a period of observation in the inpatient unit, where symptoms continued long after the amphetamines had been excreted. Such schizophrenic symptoms are known to be exacerbated by these drugs (Connell, 1958).

\section{TREATMENT}

Treatment of amphetamine users followed the lines previously recommended (Connell, 1966, 1968a). Except in rare instances amphetamines were not prescribed, because of their widespread illicit availability and the danger of toxic effects if the prescribed dose was to be supplemented by illicit use. The few exceptions who were "maintained" on amphetamines were usually older persons outside the "drug scene" who had been receiving amphetamines from general practitioners. Maintenance of young persons on amphetamines is most unlikely to be an effective "treatment," yet some $25 \%$ of the younger patients in this series were receiving amphetamine prescriptions from general practitioners (whose prescribing habits are known to vary widely (Kiloh and Brandon, 1962; Hood and Wade, 1968)) after starting their drug abuse illicitly. Our findings confirm previous observations (Connell, 1965b) that a probation order, preferably with a condition of attendance at a clinic, at least ensures attendance in most cases and the possibility of treatment.

Unlike opioid addicts, those dependent on amphetamines are not notifiable to a central agency. Thus there is no central source from which data can be obtained about the other medical sources supplying a patient with such drugs. This is a considerable handicap to treatment, and since amphetamines are so often the first drugs misused by opioid users (Bewley, 1968; Hicks, 1969; Gardner and Connell, 1971) and the present "drug scene" started with a wave of amphetamine misuse (Connell, 1964, 1965a; Sharpley, 1964) there would seem to be a strong case for notification of all amphetamine misusers. In this way early discovery and early referral for treatment and rehabilitation might be possible before the individual has become involved in the intravenous use of amphetamines, opioids, or other drugs. The extent of the problem would also be more accurately defined if notification were supplemented, in particular, by surveys of schools or centres of higher learning (30\% of the present series had started amphetamine misuse before the age of 16) and even more so if such surveys included analysis of the urine for the presence of drugs.

\section{PREVENTION}

Control of availability is clearly an important factor, and voluntary withdrawal of methamphetamine ampoules in October 1968 and of amphetamine sulphate powder (Pharmaceutical fournal, 1969) led to the disappearance of these preparations from the "drug scene." Evaluation of voluntary restrictions on prescribing such as the Ipswich agreement (Wells, 1970) and more recent ones will be important. The education of doctors, medical students, and others concerning the uses and dangers of amphetamines (Connell, 1968b; Department of Health, 1970) remains an important priority in the field of prevention.

Our thanks are due to Miss B. Kinsley for statistical help. Requests for reprints should be addressed to Dr. P. H. Connell.

\section{References}

Advisory Committee on Drug Dependence (1970). The Amphetamines and Lysergic Acid Diethylamide ( $L S D)$. London, H.M.S.O.

Bewley, T. H. (1968). British Medical fournal, 1, 727

Connell, P. H. (1958). Amphetamine Psychosis. London, Oxford University Press.

Connell, P. H. (1964). British Fournal of Addiction, 60, 9.

Connell, P. H. (1965a). Proceedings of the Royal Society of Medicine, 58, 409.

Connell, P. H. (1965b). Proceedings of the Leeds Symposium on Behavioural Disorders, p. 10. Dagenham, May \& Baker.

Connell, P. H. (1966). Fournal of the American Medical Association, 196, 718.

Connell, P. H. (1968a). Proceedings of the Royal Society of Medicine, 61, 2 178 .

Connell, P. H. (1968b). Practitioner, 200, 234

Connell, P. H. (1968c). In Drugs and Youth, ed. J. R. Wittenborn, H. Brill J. P. Smith, and S. A. Wittenborn, p. 125. Springfield, Illinois, Thomas Connell, P. H. (1968d). In The Pharmacological and Epidemiological Aspects of Adolescent Drug Dependence, ed. C. W. M. Wilson, p. 41. Oxford, Pergamon Press.

Connell, P. H. (1970). Proceedings of the Lausanne Institute on the Prevention and Treatment of Drug Dependence, p. 163. Lausanne, International Council of Alcohol and Addictions. 
Department of Health and Social Security. (1970). Amphetamines, Barbiturates, LSD and Cannabis-Their Use and Misuse. London, H.M.S.O.

Gardner, R., and Connell, P. H. (1970). Lancet, 2, 455.

Gardner, R., and Connell, P. H., (1971). Bulletin On Narcotics, 23 (4), 9.

Hawks, D., Mitcheson, M., Ogborne, A., and Edwards, G. (1969). British Medical fournal, 2,715 .

Hicks, R. C. (1969). British fournal of Addiction, 64, 235.

Hood, H., and Wade, O. L. (1968). Lancet, 2, 96.

Inghe, G. (1969). In Abuse of Central Stimulants, ed. F. Sjoqvist and M. Tottie, p. 187. Stockholm, Almqvist and Wiksell.
Interdepartmental Committee on Drug Addiction (1965). Second Report. London, H.M.S.O.

Kiloh, L. G., and Brandon, S. (1962). British Medical fournal, 2, 40.

Kramer, J. C., Fischman, V. S., and Littlefield, D. C. (1967). Fournal of the American Medical Association, 201, 305.

Pharmaceutical fournal, 1969, 202, 257.

Rylander, G. (1966). In Proceedings of the 4th World Congress of Psychiatry, I.C.S. No. 150, p. 1363. Amsterdam, Excerpta Medica.

Scott, P. D., and Willcox, D. R. C. (1965). British fournal of Psychiatry, 111, 865.

Sharpley, A. (1964). Evening Standard, 3, 4, 5, and 6 February, 1 May.

Wells, F. O. (1970). British Medical fournal, 2, 361.

\section{Footballer's Migraine}

\section{W. B. MATTHEWS}

\section{Summary}

Classical migraine, including incapacitating visual field defects, repeatedly developed in five young men immediately after blows to the head whike playing football and in no other circumstances. A similar condition occurred in a professional boxer and an isolated attack in a boy footballer. Prophylactic treatment with ergotamine tartrate may not be wholly successful and it may be necessary to give up the sport. Any unitary theory of causation of attacks of migraine must account for prodromal symptoms immediately after head injury.

\section{Introduction}

Migraine may be a formidable obstacle to the enjoyment of life but is less well known as an occupational hazard and a threat to professional advancement. I have encountered classical migraine, including incapacitating visual field defects, occurring only when playing football and precipitated by head trauma, in five young men-two whole-time professionals, one a part-time professional, and two amateurs. Two, including the part-time professional, had given up the game on this account.

\section{Case Reports}

Case 1.-A whole-time professional footballer aged 22 consulted me in 1965 with a history of seven almost identical episodes in the previous six years. Although they varied in severity, the attacks followed a set pattern. All had occurred while playing football and all had been precipitated by a blow on the head. On a few occasions early in his career this had consisted of deliberate heading of the ball, but more recently symptoms had followed accidental blows either from the ball or from another player. Within two minutes he would develop tunnel vision, which naturally greatly reduced his effectiveness on the field and he would have to come off. The visual disturbance might last for as long as an hour and would later be accompanied by tingling in one or other hand, spreading to the face, and followed by severe generalized headache and vomiting. He had never experienced similar symptoms or indeed any form of headache in any other circumstances. There were no abnormal physical signs. His career obviously depended on his being able to sustain minor blows on the head without having to leave the field, and the prophylactic use of ergotamine tartate seemed justified. The taking of $1 \mathrm{mg}$ before a practice match had no adverse effect and for the next year he took this dose

University of Oxford, Churchill Hospital, Headington, Oxford W. B. MATTHEWS, D.M., F.R.C.P., Professor of Clinical Neurology before each match. This did not afford complete protection as in 1966 he developed a typical attack after a severe blow on the face, sufficient to crack two teeth. Recent postal follow-up by courtesy of the club doctor showed that he had not taken ergotamine for the past year and had been free of attacks. Personal follow-up by television shows that he has no inhibitions about heading a football.

Case 2.-An undergraduate of 22 was a keen footballer, but from the age of 15 he had experienced episodes of blurred vision, occurring only after heading the ball. He would immediately develop ill-defined gaps in the visual field and would continue playing only with difficulty. After the game he would feel sleepy and would then develop severe headache and nausea, lasting for several hours. These attacks occurred perhaps twice a year. Two months before I saw him he had been accidently struck on the head by a ball and this had been immediately followed by one of his usual attacks, although the visual defect was more pronounced than usual and he had to leave the field and was taken to a hospital casualty department. After this he found that in every game heading the ball would induce one of his attacks and he had to stop playing. He never experienced similar attacks in any other circumstances. Physical examination and skull $x$-ray picture were normal.

An isolated attack of classical migraine in young boys following a blow on the head at football is not uncommon, but $I$ have been unable to ascertain whether this is the forerunner of ordinary migraine or is confined to minor injuries at football.

Case 3.-A boy of 12 was playing somewhat inexpertly in goal when he was struck on the side of the head by the ball. Within a few minutes he complained of blurred vision and a little later developed numbness of the right hand and difficulty with speech. As this improved, it was followed by severe headache and he was taken to a hospital casualty department by an alarmed games master. The almost equal alarm aroused in the casualty officer was allayed by the boy's rapid recovery and when I saw him a few days later he was quite well. He had no previous history of migraine and his subsequent progress is unknown.

The only other gainful occupation in which the head is necessarily and expressly exposed to trauma is boxing.

Case 4.-A part-time professional featherweight boxer aged 20 consulted me in 1968 because in the previous two months he had experienced four attacks of blurred vision and headache. These had all occurred while boxing and had immediately followed "a good punch" to the head. He thought that his vision would go black for a moment and he would then have tunnel vision, with the peripheral field "like being under water." After about 30 minutes this would be followed by severe generalized headache. All these attacks had occurred while sparring and not during a fight. He had never had similar symptoms at any other time. There were no abnormal physical signs. I advised him to give up boxing as I thought it unlikely that he would achieve much success and he ran the risk of severe punishment. He was reluctant to accept this advice and recent attempts at postal follow-up have been unsuccessful. 